\title{
Parent and School-Age Children's Food Preparation Cognitions and Behaviors Guide Recommendations for Future Interventions
}

\author{
Melissa D. Olfert, DrPH, RD ${ }^{1}$; Rebecca L. Hagedorn, $\mathrm{BS}^{1}$; Miriam P. Leary, PhD, RCEP ${ }^{1}$; \\ Kaitlyn Eck, MS, RD ${ }^{2}$; Karla P. Shelnutt, PhD, RD ${ }^{3}$; \\ Carol Byrd-Bredbenner, PhD, RD, FAND ${ }^{2}$
}

\begin{abstract}
Objective: To investigate parent and child food preparation cognitions and behaviors qualitatively to create recommendations for nutrition programs targeting these audiences.

Design: Focus groups were conducted in community settings with school-age children $(\mathrm{n}=37)$ and parents $(\mathrm{n}=38)$ in Florida, West Virginia, and New Jersey.

Setting: Community settings in Florida, West Virginia, and New Jersey.

Participants: School-age children $(\mathrm{n}=37)$ and parents $(\mathrm{n}=38)$.

Phenomenon of Interest: Factors influencing food preparation of school-aged children and their parents to inform Social Cognitive Theory-based recommendations.

Analysis: Content analysis.

Results: Parents believed that child involvement in meal preparation was important for developing cooking skills, responsibility, and self-esteem, but noted that involvement was limited by time scarcity and concern regarding child safety in the kitchen. Parents recommended having children engage in ageappropriate food preparation activities, such as packing their own snacks. Children echoed parents' beliefs, stating they would need to know how to cook later in life. Many children acknowledged being a part of meal preparation by setting the table and helping grocery shop. Food preparation's link to improving diet quality was not mentioned by parents or children. To increase involvement, children suggested that parents demonstrate skills, select age-appropriate tasks for them, and reward them for helping.

Conclusions and Implications: This research provides insight into parents' and children's food preparation cognitions (eg, beliefs, attitudes) and behaviors and assembles results into recommendations that may guide decisions during nutrition intervention development and potentially improve nutrition intervention. Key Words: children, cooking, focus groups, parents, Social Cognitive Theory (J Nutr Educ Behav. 2019; 51:684-692.)
\end{abstract}

Accepted January 28, 2019. Published online March 8, 2019.

\section{INTRODUCTION}

Recent estimates indicated that nearly 1 in 5 school-age children (ie, aged 611 years) in the US is obese. ${ }^{1}$ This is a crucial public health concern because the negative health consequences associated with childhood obesity are numerous and include early onset of chronic diseases, vascular disease, and type 2 diabetes. $^{2,3}$ Many lifestyle behaviors have been identified as contributors of childhood obesity, including poor diet. ${ }^{4}$ Parental support and

\footnotetext{
${ }^{1}$ Department of Animal and Nutritional Sciences, West Virginia University, Morgantown, WV

${ }^{2}$ Nutritional Sciences Department, Rutgers University, New Brunswick, NJ

${ }^{3}$ Department of Family, Youth, and Community Sciences, University of Florida, Gainesville, FL Conflict of Interest Disclosure: The authors have not stated any conflicts of interest.

Address for correspondence: Melissa D. Olfert, DrPH, RD, Department of Animal and Nutritional Sciences, West Virginia University, 1194 Evansdale Drive, Agricultural Science Building, Morgantown, WV 26506; E-mail: melissa.olfert@mail.wvu.edu

(C) 2019 The Authors. Published by Elsevier Inc. on behalf of Society for Nutrition Education and Behavior. This is an open access article under the CC BY-NC-ND license. (http:// creativecommons.org/licenses/by-nc-nd/4.0/)

https://doi.org/10.1016/j.jneb.2019.01.022
}

the home environment are important factors influencing childhood obesity prevention, and in particular, children's diets. ${ }^{5,6}$

One area in which parents can improve diet quality and positively influence the home environment for childhood obesity prevention is teaching children food preparation skills and engaging them in family meal preparation. Often, dietary recommendations are not met because of inadequate nutrition coupled with limited food preparation knowledge and skills. ${ }^{7}$ As an essential component of healthy living, food preparation skills are needed to produce appetizing, healthy foods. ${ }^{8}$

A parent-child dyad childhood obesity prevention program $^{8}$ that 
included hands-on cooking activities demonstrated improvements in cooking skills and eating habits. Indeed, cooking in the home is associated with better diet quality in children, including higher fruit and vegetable and macro- and micronutrient intakes (including increased protein and vitamin $C$ intake ${ }^{9}$ ) and lower intakes of fat, fried foods, and sugar-sweetened beverages. $^{10-12}$ Children who are involved in food-related activities have increased nutrition awareness, including the role of food in energy balance $^{9}$ and self-efficacy for selecting and eating healthy foods. ${ }^{13}$ In addition, greater frequency of helping with food preparation enhances children's fruit and vegetable preferences. ${ }^{13}$ As children's self-efficacy for cooking increases, so does the frequency of family dinners: ${ }^{14}$ eating together as a family offers an array of health benefits. ${ }^{15-21}$ In addition to dietary intake improvements, childfocused meal preparation correlates positively with other eating-related behaviors, such as improving eating enjoyment and reducing picky eating behaviors. $^{22}$

Aside from better diet quality and eating practices, engaging children in cooking at home confers a range of other benefits including closer family bonds. Because children like to eat what they cook and want to help their parents, $^{23,24}$ it is unsurprising that spending time together is a frequently reported benefit of families cooking together. ${ }^{22}$ Indeed, a reason why children enjoy cooking is because of the opportunity to spend more time with parents. ${ }^{14}$ Cooking activities also stimulate positive feelings in children, including independence, ownership, pride, and self-esteem. ${ }^{23,25,26}$ After a single meal preparation session, children reported feeling more positive and in control. ${ }^{22}$

Gaining food preparation skills benefits children now and in the future. With the rising prevalence of childhood obesity, the role of food preparation behaviors within the home is an important area warranting investigation. Encouraging children to be more involved in home meal preparation could be an effective health promotion strategy, ${ }^{13}$ and nutrition education programs that teach children to prepare simple and healthy meals could lead to improved dietary habits. Nutrition education programs are needed that develop children's cooking skills and parents' ability and propensity to teach these skills to children. Although the most effective health programs are guided by a firm understanding of factors associated with performing (or not) a particular behavior, $^{27-29}$ understanding of factors affecting children's food preparation skill development in the home remains limited. Hence, this investigation was conducted to investigate children's food preparation cognitions and behaviors qualitatively, as reported by parents and school-age children (6-11 years) for the purpose of creating recommendations based on the Social Cognitive Theory $(\mathrm{SCT})^{27-29}$ that could be incorporated into food preparation programs for families with school-age children.

\section{METHODS}

The institutional review boards for protection of human subjects from Rutgers University, the University of Florida, and West Virginia University approved this investigation. Parents gave informed consent for themselves and their children. Children gave verbal assent before participation.

\section{Participants}

Parents with school-age children (aged 6-11 years) who lived in Florida, West Virginia, or New Jersey were recruited to engage in a 60-minute focus group discussing home environments and lifestyle practices. Recruitment announcements were in both English and Spanish and were distributed at community locations (eg, recreation centers, schools, worksites) and posted electronically (eg, social media Web sites, e-mail listservs). These announcements indicated that the focus groups with parents would last approximately 1 hour and that parents would be paid \$25 for participation. Recruitment announcements also informed parents that their school-age children could participate in 30-minute focus group discussions and be compensated \$15. Parent participation did not depend on their child's participation, or vice versa; thus, parent and child participants were not necessarily related.

\section{Instruments}

Parents completed a short form that gathered demographic information (eg, age, highest education level, number and ages of children) before the start of the focus groups. Children also completed a brief demographic information form before engaging in focus group discussions.

A semistructured focus group guide was developed and pilot-tested using standard procedures. ${ }^{30,31}$ Bandura's $\mathrm{SCT}^{28}$ provided the structure for the focus group guides, which explored food preparation cognitions, barriers, and facilitators. For example, to explore parents' cognitions toward children's food preparation, parents were asked to describe how much their children were involved in preparing meals or snacks for themselves or their family, which provided the segue to probe questions to gain an understanding of factors affecting children's involvement in food preparation (eg, parent outcome expectations vis-à-vis development of children's food preparation, parent self-efficacy for teaching children food preparation skills, barriers faced). To identify facilitators, parents were asked, What would help your kids develop basic cooking skills? Focus groups were conducted by a team of 2 researchers, 1 of whom moderated the group; the other served as a notetaker. All researchers completed formal training and practice sessions to standardize data collection across researchers and focus group sites. Discussions with parents were conducted in their primary language (ie, English or Spanish). Children's focus groups were conducted in English because all were fluent in this language. Focus groups with younger children (aged 6-9 years) were conducted separately from those composed of older children (aged 9-11 years). Focus groups were intentionally kept small to ensure that everyone was able to participate fully. The notetaker took comprehensive notes of focus group discussions and refined them within 48 hours. The moderator reviewed the notes for clearness, completeness, and accuracy. Spanish language focus group notes 
were translated into English by the notetaker of the focus groups. Both researchers independently reviewed the notes and then conferred to reach common agreement on their contents.

\section{Data Analysis}

Descriptive statistics summarizing demographic data were generated with SPSS software (version 21.0, IBM, Armonk, NY, 2012). Data are reported as means \pm SD. Qualitative focus group data were content analyzed individually by 3 trained researchers to detect thematic trends. ${ }^{32,33}$ Standard content analysis procedures were employed because they produce objective, systematic descriptions ${ }^{34}$ that permit drawing "replicable and valid inferences from the data to their context." 35, p 21 Researchers compared their individual content analyses and discussed them to reach consensus. Data were analyzed throughout data collection to determine when data saturation was achieved, at which time data collection ceased. $^{33,36}$ The researchers then reviewed responses to determine congruence across geographic regions as well as language spoken by parents, to determine whether data could be pooled.

\section{RESULTS}

Parents $(\mathrm{n}=38)$ from 3 states $(12$ from New Jersey, 14 from West Virginia, and 12 from Florida) participated in 1 of 13 focus group discussions addressing children's food preparation activities, averaging 3 parents/group. The majority of parents were mothers (95\%) who had at least some postsecondary education (71\%). Mean age of parents was $37 \pm 6$ years; they reported an average of $2 \pm 1$ children aged $<18$ years living in their homes. Most parents completed the focus groups in English vs Spanish (68\% and $32 \%$, respectively).

Similarly, children $(n=37)$ participated in 1 of 12 focus group discussions, averaging 3 children/group (2-3/group for younger children and 3-4/group for older children). Children (males $=51 \%$ ) were an average age of $9 \pm 2$ years. Children reported having $1 \pm 1$ younger and $1 \pm 1$ older sibling. Four focus groups were held in each state, and participants were nearly evenly distributed across these locations (13 in New Jersey, 12 in West Virginia, and 12 in Florida).

Content analysis results identified an array of themes related to children's food preparation (Table 1), which are discussed subsequently.

\section{Parent Focus Groups}

A comparison of themes emerging from parent focus group content analysis across geographic location and language revealed no differences. Thus, data were pooled.

Parents' attitudes toward children participating in food preparation. Parents reported that getting children involved in the kitchen was important because it helps to develop cooking skills. One mother remarked, "When I was little, I always got kicked out of the kitchen. But they [her children] come in and are curious, so I have them help or just watch." Several parents noted that children want to learn and reported that their children's interest in cooking stemmed from watching cooking shows on television. For children to learn how to cook, parents felt "they need to watch me doing things in the kitchen," so parents started teaching children by "watching and maybe allowing them to help a little bit if it's appropriate." A few parents were hesitant to involve children in the kitchen, because the parent "likes to be in charge" of the cooking or because "sometimes we're in a rush" and involving children can slow down the food preparation process. Another commented, "They are young, so I don't like them to prepare foods."

Parents thought that getting children involved in meal preparation offered benefits beyond learning cooking skills; they commented that food preparation activities "teaches them to be responsible" and builds self-esteem ("they feel useful helping out, and that makes them very happy"), and self-management (when "actively engaged" [in household chores like cooking], "they become a lovely child"). To reap these benefits, parents indicated that it was important to "try to keep it simple, fun, and engaging" for children.
Parent reports of children's food preparation activities. Parents indicated that children had varying levels of participation in food preparation. Some regularly included children by "giving each of my kids a responsibility, like chopping or stirring." Parents stressed the importance of "giving [children] responsibilities that are age appropriate" and matching their skill levels. Therefore, the way parents included children in cooking activities varied greatly. Some parents reported that their children were able to complete simple steps that contributed to the overall preparation process, such as "crack and beat eggs, peel potatoes, and dump from the measuring cup to the bowl," and help with meal service activities, such as "pour milk and drinks". Others indicated that children were able to prepare simple meal items, noting that children could "make sandwiches, grilled cheese," and "serve themselves cereal with milk and make smoothies, pancakes, and baked goods." One mother of a 10year-old indicated that he could "brown hamburger meat, boil water, and scramble eggs."

Breakfast was commonly named as a meal that children helped prepare and serve themselves. Parents found that this meal provided a good opportunity for children to engage in cooking activities. For example, 1 mother reported that "when we have more time on the weekends, the smaller one [younger child] likes to prepare breakfast." Another remarked, "If they want pancakes in the morning, I say 'Okay, then help me,' and I will give them each responsibilities." Others reported that they allowed children to "help with breakfast if it doesn't involve the stove." However, children were permitted to use small kitchen appliances to make toast and smoothies. Parents noted a particular benefit to children preparing their own breakfast, saying, "I like to sleep in, but they know what they can have. They can make whatever they want, but don't wake me up."

Some parents felt that patience and supervision were critical when children were helping in the kitchen, because children were just learning and were likely to make mistakes. One mom discussed the importance 
Table 1. Key Themes Emerging From Parent and Child Focus Group Data

\section{Parent Themes}

Attitudes toward child participation in food preparation

Child participation in food preparation is important for these reasons:

Develops cooking skills

Promotes learning

Teaches responsibility and self-management

Builds self-esteem and independence

Barriers to child participation in food preparation

Parent desires control

Parent's time scarcity

Safety concerns

Facilitators of child participation in food preparation

Giving tasks that are age-appropriate and matched to child's skill level

Desire to satisfy children's curiosity related to food prepa ration

Recognition of opportunities to involve children

Understanding of benefits to children of including them in food preparation activities

Patience by parent

Parental supervision

Willingness to accept quality of children's work

\section{Child Themes}

Attitudes toward learning to prepare food

Learning to prepare food is important for these reasons:

Helps their family now

Prepares for the future

Teaches self-reliance

Teaches parents

Children learn how to prepare foods correctly

Children learn safety procedures

Barriers to participation in food preparation

Lack of knowledge

Fear of hot appliances

Lack of interest

Parent does not allow participation in food preparation

Facilitators of participation in food preparation

Recognition of responsibilities in family

Parents set rules and children comply with them

Awareness that cooking requires learning and skill devel opment

Concern about future

Desire to learn

Parents ask children to help with food preparation

Parents teach children to prepare food

Parents allow children to take on responsibility

Children telling parents they want to help and how they can do it of giving children a chance to try even if it made more work for the parent: "She wants to wash [the dishes]; I let her do it and then I'll go back and fix it. I think she is getting [the hang of] it. There's motivation." Other parents reported that vigilance was important to maintain a safe environment:

\section{Sometimes the kids will walk away from the food [on the stove] and you have to teach them to pay attention. They occasionally burn things and they end up learning from it.}

Parent concerns about children's food preparation activities. Parents were concerned about children's safety in the kitchen, particularly related to using the oven and stove. Parents worried that children would be burned, particularly when they were "not tall enough for the stove without a stool." Although this worry limited children's food preparation activities, parents identified numerous ways to include children that did not involve heating foods:
If we are cooking something, then maybe I will let them wash the vegetables and cut them, but cooking food, no. When I'm preparing beans, I'll let her put everything in the beans and then I'll put it on the stove. She puts everything together then I'll put it in the oven.

Other opportunities included having children

pack lunch for school, set the table, serve the drinks, clean up their plate after a meal, put dishes in the sink, and wash dishes or load the dishwasher.

Parents also got children involved in meal planning by asking them to "help pick out things in the grocery store."

Selecting snacks and packing lunch were frequently mentioned by parents as other opportunities for children to engage in food preparation without needing to use the stove, as well as giving children some autonomy over their food choices. Parents noted that school-age children "like to do things alone and not have help from mom," so they provided opportunities for children to take responsibility for their own food choices while allowing parents to continue to influence intake covertly by monitoring what their child chooses to pack for lunch or eat for snack "so [they] don't snack on empty calories the whole day," and by setting requirements for what should be packed for lunch or "making sure we buy [healthy] food for them to pack."

\section{Child Focus Groups}

Qualitative analysis of children's focus group data revealed no differences by geographic location or age group. Thus, children's data were aggregated.

Children's perceptions of their food preparation skills. Children identified a variety of foods that they were able to prepare, ranging from simple (eg, a bowl of cereal) to complex (eg, Shepherd's pie). Foods that children commonly reported preparing included pancakes, eggs, toaster waffles, boxed macaroni and cheese, smoothies, 
slushies, and sandwiches. Some children were confident in their cooking skills and felt that they could prepare "everything boxed or with instructions" and believed that "if I have a recipe, I can do it." Children also indicated that they had some basic food preparation skills such as being able to peel vegetables and cut some fruits and vegetables. Most children reported that they were able to use the microwave to heat foods, but many were "afraid of taking things out of the oven" and "don't like to be around hot or boiling water." In many cases, this was because of a previous burn.

Children's involvement in family meal preparation. Children noted that when preparing for a meal,

We all have different roles in the family for setting up the table, such as cooking, putting a cloth on the table, setting out plates and utensils.

Children commonly reported being involved by setting the table, pouring drinks, and washing dishes. Children also helped by "going to the grocery store with Mom to help her get things from the store" and realized that this was only helpful if they "picked things from the list rather than go nuts and wander off and ask for toys." Children also mentioned that they helped by "helping Mom babysit the younger kids while she cooks and make it easy on Mom and eat [what she cooks]," meaning reducing conflict related to mealtime intake. Although most children engaged in food preparation activities, it was minimal for some:

I don't really help make food, here and there, but I don't really; I don't know how; I am not interested in helping [prepare foods]; and Mom won't let us help with the cooking.

Children's perceptions of the importance of knowing how to prepare foods. Children believed it was important to know how to cook, for a variety of reasons including the necessity of cooking as an adult, caring for others, and making quality foods. Children understood that cooking was a learned skill, commenting that you had to "get the practice of cooking." Most focused on the importance of learning to prepare foods so that they could make meals as adults ("for when you get older, for in college. You can't eat pizza every day!"). Children also felt a need to know how to cook so they could care for their future families ("You need to know how to cook for your kids when you're a grownup!"), aging parents ("When my parents get older, I can help them and make food for them and bring them food"), and changing family circumstances ("Soon, I will be the one doing everything, because my brother is going away to college, so I need to know how to do stuff").

Other children prioritized learning how to cook because "It might make me a better person-because you are helping people [in your family]." Some realized that if they learned how to cook, "When your parents are stressed, you can make the meal and they can relax and watch something." They also felt that knowing how to cook would be beneficial because "If someone is sick, you are going to have to do it, or if they are stressed." Another child mentioned that "It's important to learn how to cook so that, if your mom or dad doesn't know how to cook, you can show them with some easy recipes." There were also children who thought that learning to cook was important "so I know how to make family meals the right way and do it safely," and "so you don't get hurt."

One child made the connection between learning how to cook and helping the family be more financially stable:

Yes, it is important to know how to make meals because, if I have the time, I try to make my parents breakfast in the morning on the weekends when they sleep in (so they can work harder and make money to buy useful stuff for us). I also want them to be prepared for the day and have the energy to work hard by making them a good breakfast.

Children also believed that learning to cook would help them produce quality foods, indicating that "When I try to experiment and may try something new or different, sometimes it comes out horrible," so it's "important to know how to cook so you don't mess things up [and can make it turn out good]." Moreover, "you know how to make something for yourself when you get hungry." Finally, 1 child thought that learning how to cook was important "because it is all about spending time with your family." Another child related that it was not important to learn how to cook because "Mom cooks," and yet another agreed that it was important to learn to prepare foods, "but I still don't help."

Children's suggestions for getting kids involved in making meals. Children said that they would be more likely to help make meals if parents ask kids politely to help or give children treats for helping. Children also emphasized the need for parents to "show kids slowly [how to prepare meals] so they can make meals safely" and choose age-appropriate tasks for children. Parents could prepare foods that are "self-serving" [customizable]. For example, self-serve tacos and burritos to get children involved in adding their own toppings. "Having a routine and knowing you have chores to do before dinner" was another strategy suggested by children who believed that parents' rules, such as "You don't get your electronics until you help with dishes or set the table" could be a helpful motivator for getting children involved in preparing food.

Children indicated that they could contribute to family meal preparation efforts by taking action "I recommend those kids to prepare a good breakfast like waffles in a toaster for their parents"), asking to help, or telling their parents what they thought they can do to help ("I say, Mom, I can do the tortillas"). Reminding parents that "the whole process will go quicker" if children helped and that parents "will have more time to relax" and so should "go do what they need to do" while the children "take care of it all [prepare the whole meal]" was another way in which children thought they could get parents to allow them to participate in meal preparation more often. Some children wanted to help more, but 
parents don't want us to help and Mom won't let us because she is in a bad mood, and it is sometimes just easier for her to do it on her own.

\section{DISCUSSION}

The purpose of this study was to investigate children's food preparation cognitions and behaviors qualitatively, as reported by parents and school-age children (age 6-11 years) with the goal of using the findings to create recommendations based on the SCT, ${ }^{27-29}$ to guide the development of nutrition education programming for these audiences. Table 2 lists recommendations derived from the study findings organized by SCT construct.

The findings indicated that both parents and children believed that youth involvement in meal preparation was important to develop cooking skills. Food preparation frequency varied in the literature, ${ }^{11,14,37}$ but was consistently low, highlighting that many children are not involved in mealtime activities. In this study, however, most children engaged in at least some foodrelated activities and food preparation skills ranging from simple (eg, a bowl of cereal) to complex (eg, Shepherd's pie). This is important because evidence suggests that establishing cooking and meal preparation proficiency at an early age in children can lead to a lifetime of healthy nutrition, eating behaviors, and ultimately, weight management. ${ }^{38}$ Furthermore, helping with meal preparation can improve food choices as well as fruit and vegetable intake in youths. $^{37}$ Therefore, it was recommended $^{14}$ that involvement in meal preparation has positive nutritional outcomes and should be prioritized in nutrition education. Improving outcome expectations related to child food preparation skills (ie, the belief that learning food preparation skills has important outcomes, including improved diet quality or weight management) could motivate parents to provide more opportunities for children to participate in activities that increase children's food preparation skills, and perhaps also those of parents.

Although parents recognized the importance of engaging children in food preparation, they acknowledged barriers that limited children's involvement in cooking. A commonly perceived barrier identified by parents was the time required to involve children in the cooking process. This finding was well supported by literature ${ }^{39,40}$ indicating that time was an important barrier to overcome to ensure children's involvement in mealtime. Parent-tested strategies to manage time included having children complete simple steps for the overall preparation process (eg, stirring) and to prepare simple meal items (eg, make sandwiches) and fix breakfast (eg, cereal with milk). These practices would likely encourage selfefficacy and nutrition awareness in children and could easily be incorporated into busy family lifestyles.

Another common barrier cited by parents was concern about children's safety in the kitchen, primarily fear of burns (eg, the stove, oven, and boiling water); children echoed this concern. Zuckerman and Duby ${ }^{41}$ emphasized that parents need to know specific cognitive and physical limitations in children at different ages so that clear safety rules can be

Table 2. Recommendations for Interventions Targeting Improved Meal Preparation Behaviors in Families With School-Age Children

\section{Social Cognitive Theory Construct}

Outcome expectations

Outcome expectations

Outcome expectations

Outcome expectations

Facilitation

Facilitation

Facilitation

Facilitation

Facilitation

Facilitation/observational learning

Facilitation/outcome expectations

Self-efficacy

Observational learning
Recommendations for Future Interventions Promoting Improved Meal Preparation Behaviors

Expand food preparation outcome expectations to include healthier diets.

Expand food preparation outcome expectations for children to include improved weight management.

Expand food preparation outcome expectations for children to include improved feelings of self-worth.

Expand food preparation outcome expectations for parents and children to include improved family time.

Promote factors to overcome barriers to food preparation related to food safety.

Provide parents and children with ideas for expanding food preparation options beyond meal skills (eg, setting the table, washing dishes).

Increase parents' repertoire of age-appropriate food preparation skills for children

(eg, washing vegetables, browning meat, peeling eggs).

Help parents build child food preparation planning skills.

Provide reminders about benefits of shared food preparation skills for children.

Share parent-tested and child-recommended strategies to increase frequency of shared food preparation.

Teach parents about nutritional impact of teaching children food preparation skills to help them understand how their investment in these efforts can support healthy diets and child health.

Build children's confidence in their ability to prepare food and meals on a regular basis.

Encourage parents to demonstrate food preparation skills to young children. 
established. Furthermore, a study of middle school students ${ }^{42}$ found that this age group lacked food safety knowledge, indicating a need to improve child food safety knowledge and skills as well as with cooking skills. Therefore, education programs for both parents and children that aim to increase children's food preparation skills also should incorporate food safety education and establish age-appropriate safety rules for children. However, there is little evidence regarding age-appropriate food preparation techniques for children; ${ }^{14}$ thus, recommendations provided by parents in the current study may provide insight into this topic.

To foster children's learning in the kitchen in a timely and safe manner, parents' recommendations included having children watch and eventually allowing them to contribute with small, age-appropriate steps. Children echoed this by acknowledging that food preparation was a learned skill and recommended that parents demonstrate skills and give them ageappropriate tasks to perform. This use of parent demonstration was employed in previous childhood obesity programming to facilitate behavior change through the SCT. ${ }^{43,44}$ In addition, some parents recommended allowing children to select snacks or pack their own lunch, with parental monitoring or rules, which gave children autonomy over their food choices. This may be beneficial because controlling children's food choices was associated with poor eating patterns, ${ }^{45}$ and therefore learning to make proper food choices as a child can foster positive nutritional outcomes. Incorporation of these childapproved strategies can inform child nutrition education programs aiming to increase children's involvement in food preparation.

However, other contributions cited by parents and children were not food specific; both groups repeatedly mentioned other mealtime contributions, such as setting the table or washing dishes. Although these are important mealtime contributions, they may not necessarily confer the same benefits as cooking or food preparation-specific roles. Involvement in food preparation increases diet quality and nutrition awareness in children, ${ }^{10-13,22}$ but if children are not actively working with food during mealtime preparation, they may not develop the skills, attitudes, and behaviors that contribute to healthier diets. Therefore, future research is warranted to determine whether meal preparation assistance, but help that does not develop food-specific skills, elicits the benefits of improvements in overall diet quality as well as self-worth.

To the authors' knowledge, this is one of the first studies to analyze parent and children's attitudes and beliefs related to food preparation qualitatively; therefore these findings can contribute meaningfully to future research, as well as the development of nutrition education programs aiming to improve dietary intake, which in turn can support childhood obesity prevention. Nevertheless, this study had limitations. First, the study's sample size was limited, although data saturation was achieved. Age, sex, and ethnic differences were difficult to infer in study participants owing to the limited sample size. Furthermore, the study was limited to 3 geographical locations. Responses might have reflected regional characteristics, but geographical analysis was not in the analytical design. Finally, this sample may not represent the general population because of self-selection bias. Nonetheless, the data captured from parent and child focus groups were rich, informative, and impactful. This study's results, as well as the recommendations presented in Table 1, may be used to inform the development of future nutrition interventions aimed at improving food preparation skills in school-age children.

\section{IMPLICATIONS FOR RESEARCH AND PRACTICE}

School-age children are beginning to make their own decisions related to diet and eating; thus, this age group offers an ideal period in which to intervene, especially with education. School-age children rely on their parents for many health-related decisions. Consequently, it is important to understand the cognitions of both parents and children to develop interventions targeting children. Although the parents in this study recognized some of the interpersonal benefits of children assuming responsibility in food preparation, such as increased self-esteem, child focus group participants did not identify these benefits. Teaching parents to expect these selfworth building benefits (eg, pride, selfconfidence, and independence) linked to food preparation ${ }^{13,22,23,25,26,46}$ could convince them to make food preparation opportunities more available to children, perhaps even promoting action in parents who were resistant to children preparing food. The selfworth benefits, especially feelings of self-efficacy, might extend beyond food preparation to support academic performance, strivings toward achievement, and coping behaviors. ${ }^{47,48}$ These findings suggest an important avenue for nutrition education programs to educate children about how learning competencies in the kitchen can lead to improved self-worth and collateral benefits in other developmental areas.

\section{ACKNOWLEDGMENTS}

The authors acknowledge the US Department of Agriculture, National Institute of Food and Agriculture, Grant No. 2017-680001-26351.

\section{REFERENCES}

1. Hales CM, Carroll MD, Fryar CD, Ogden CL. Prevalence of Obesity Among Adults and Youth: United States, 2015-2016. NCHS Data Brief No. 288. Atlanta, GA: US Department of Health and Human Services, Centers for Disease Control and Prevention, National Center for Health Statistics; 2017.

2. Gishti O, Gaillard R, Durmus B, et al. BMI, total and abdominal fat distribution, and cardiovascular risk factors in schoolage children. Pediatr Res. 2015;77: 710-718.

3. Kumar S, Kelly A. Review of childhood obesity: from epidemiology, etiology, and comorbidities to clinical assessment and treatment. Mayo Clinic Proc. 2017;92: 251-265.

4. Sahoo K, Sahoo B, Choudhury AK, Sofi NY, Kumar R, Bhadoria AS. Childhood obesity: causes and consequences. J Family Med Prim Care. 2015;4:187-192. 
5. Ebbeling C, Pawlak D, Ludwig D. Childhood obesity: public-health crisis, common sense cure. Lancet. 2002;360: 473-482.

6. Pinard CA, Yaroch AL, Hart MH, Serrano EL, McFerren MM, Estabrooks PA. Measures of the home environment related to childhood obesity: a systematic review. Public Health Nutr. 2012;15:97-109.

7. Condrasky M, Quinn A, Cason K. Cooking camp provides hands-on nutrition education opportunity. J Culinary Sci Technol. 2007;5:37-52.

8. Miller A, Franzen-Castle L, Aguirre T, et al. Food-related behavior and intake of adult main meal preparers of 910 year-old children participating in iCook 4-H: a five-state childhood obesity prevention pilot study. Appetite. 2016;101:163-170.

9. Anliker JA, Laus MJ, Samonds KW, Beal VA. Mothers' reports of their three-year-old children's control over foods and involvement in foodrelated activities. J Nutr Educ. 1992; 24:285-291.

10. Larson NI, Perry CL, Story M, Neumark-Sztainer D. Food preparation by young adults is associated with better diet quality. J Acad Nutr Diet. 2006;106:20012007.

11. Larson NI, Story M, Eisenberg ME, Neumark-Sztainer D. Food preparation and purchasing roles among adolescents: associations with sociodemographic characteristics and diet quality. J Am Diet Assoc. 2006;106:211-218.

12. McLaughlin C, Tarasuk V, Kreiger N. An examination of at-home food preparation activity among low-income, food-insecure women. J Am Diet Assoc. 2003;103:1506-1512.

13. Chu Y, Storey K, Veugelers P. Involvement in meal preparation at home is associated with better diet quality among Canadian children. J Nutr Educ Behav. 2014;46:304-308.

14. Woodruff SJ, Kirby AR. The associations among family meal frequency, food preparation frequency, self-efficacy for cooking, and food preparation techniques in children and adolescents. $J$ Nutr Educ Behav. 2013;45:296-303.

15. Van Lippevelde W, Te Velde SJ, Verloigne $\mathrm{M}$, et al. Associations between family-related factors, breakfast consumption and BMI among 10-to 12year-old European children: the crosssectional ENERGY-study. PLoS One. 2013;8:e79550
16. Hammons AJ, Fiese BH. Is frequency of shared family meals related to the nutritional health of children and adolescents? Pediatrics. 2011;127:e1565e1574.

17. Fulkerson JA, Larson N, Horning M, Neumark-Sztainer D. A review of associations between family or shared meal frequency and dietary and weight status outcomes across the lifespan. J Nutr Educ Behav. 2014;46:2-19.

18. Fulkerson JA, Friend S, Flattum C, et al. Promoting healthful family meals to prevent obesity: HOME Plus, a randomized controlled trial. Int J Behav Nutr Phys Act. 2015;12:154.

19. Dallacker M, Hertwig R, Mata J. The frequency of family meals and nutritional health in children: a meta-analysis. Obesity Rev. 2018;19:638-653.

20. Fink SK, Racine EF, Mueffelmann RE, Dean MN, Herman-Smith R. Family meals and diet quality among children and adolescents in North Carolina. J Nutr Educ Behav. 2014;46:418-422.

21. Christian MS, Evans CE, Hancock N, Nykjaer C, Cade JE. Family meals can help children reach their 5 A Day: a cross-sectional survey of children's dietary intake from London primary schools. J Epidemiol Community Health. 2013;67:332-338.

22. van der Horst K, Ferrage A, Rytz A. Involving children in meal preparation: effects on food intake. Appetite. 2014;79:18-24.

23. Dougherty K, Silver C. Chef-nutritionist teams spark enjoyment and learning in cooking education series for 8- to 12-year-olds. J Nutr Educ Behav. 2007;39:237-238.

24. Lautenschlager L, Smith C. Understanding gardening and dietary habits among youth garden program participants using the Theory of Planned Behavior. Appetite. 2007;49:122-130.

25. Heim S, Stang J, Ireland M. A garden pilot project enhances fruit and vegetable consumption among children. J Am Diet Assoc. 2009;109: 1220-1226.

26. Bowen RL, Devine CM. "Watching a person who knows how to cook, you'll learn a lot": linked lives, cultural transmission, and the food choices of Puerto Rican girls. Appetite. 2011;56:290-298.

27. Kelder S, Hoelscher D, Perry C. How individuals, environments, and health behaviors interact. In: Glanz K, Rimer B, Viswanath K, eds. Health Behavior and Health Education: Theory
Research and Practice, 5th ed, San Francisco, CA: Jossey-Bass; 2015:169-188.

28. Bandura A. A Social Learning Theory. Englewood Cliffs, NJ: Prentice-Hall; 1977.

29. Bandura A. Health promotion by social cognitive means. Health Educ Behav. 2004;31:143-164.

30. Rollnick S, Mason P, Butler C. Health Behavior Change: A Guide for Practitioners. Edinburgh, UK: Churchill Livingstone; 1999.

31. McLafferty I. Focus group interviews as a data collecting strategy. $J$ Adv Nurs. 2004;48:187-194.

32. Miles M, Huberman A, Saldana J. Qualitative Data Analysis: A Methods Sourcebook. 3rd ed. Thousand Oaks, CA: Sage; 2013

33. Harris J, Gleason P, Sheean P, Boushey C, Beto J, Bruemmer B. An introduction to qualitative research for food and nutrition professionals. J Am Diet Assoc. 2009;109: 80-90.

34. Berelson B. Content Analysis in Communications Research. New York, NY: Hafner; 1971

35. Krippendorff K. Content Analysis: An Introduction to Its Methodology. Beverly Hills, CA: Sage; 1980.

36. Sandelowski M. Sample size in qualitative research. Res Nurs Health. 1995;18: 179-183.

37. Chu YL, Farmer A, Fung C, Kuhle S, Storey KE, Veugelers PJ. Involvement in home meal preparation is associated with food preference and self-efficacy among Canadian children. Public Health Nutr. 2013;16:108-112.

38. Burrows TL, Lucas H, Morgan PJ, Bray $\mathrm{J}$, Collins CE. Impact evaluation of an after-school cooking skills program in a disadvantaged community: back to basics. Can J Diet Pract Res. 2015;76: 126-132.

39. Jabs J, Devine CM. Time scarcity and food choices: an overview. Appetite. 2006;47:196-204.

40. Fulkerson JA, Neumark-Sztainer D, Story M. Adolescent and parent views of family meals. $J$ Am Diet Assoc. 2006;106:526-532.

41. Zuckerman BS, Duby JC. Developmental approach to injury prevention. Pediatr Clin North Am. 1985;32:17-29.

42. Quick V, Byrd-Bredbenner C, Corda KW. Determinants of safe food handling behaviors among middle school youth. Nutr Food Sci. 2013;43:543-553.

43. Miller A, Franzen-Castle L, Aguirre T, et al. Food-related behavior and intake 
of adult main meal preparers of 9-10 year-old children participating in iCook 4-H: A five-state childhood obesity prevention pilot study. Appetite. 2016;101:163-170.

44. Kattelmann KK, Meendering JR, Hofer EJ, et al. The iCook 4-H Study: report on physical activity and sedentary time in youth participating in a multicomponent program promoting family cooking, eating, and playing together. J Nutr Educ Behav. 2019;51: S30-S40.

45. Scaglioni S, Salvioni M, Galimberti C. Influence of parental attitudes in the development of children eating behaviour. Br J Nutr. 2008;99(suppl 1):S22S25.

46. Hagedorn RL, White JA, FranzenCastle L, et al. Teens implementing a childhood obesity prevention program in the community: feasibility and perceptions of a partnership with HSTA and iCook 4-H. Int J Environ Res Public Health. 2018;15:E934.

47. Multon KD, Brown SD, Lent RW. Relation of self-efficacy beliefs to academic outcomes-a meta-analytic investigation. $J$ Counsel Psychol. 1991;38:30-38.

48. Bandura A. Self-efficacy mechanism in human agency. Am Psychol. 1982;37: 122-147.

\section{Panel on $\mathrm{H}$ index / Impact Factor - Cornerstone of Your Career at the SNEB Annual Conference}

The panel of JNEB editors will describe the h-index and other metrics that relate to research impact and career development. The Impact Factor and other journal metrics will be explored and discussed:

\section{Learning Objectives:}

- Will understand h-indices and how this related to their career

- Will understand Impact Factors and how this related to their research

- Will understand how to improve their h-index

https:/ / events.resultsathand.com/sneb2019/888/agenda.html\#session/29139 